Psychother. Psychosom. 1979;32:323

\title{
Closing Speech
}

F.

Askevold

Oslo

Finn Askevold, MD, Head Physician, Psychosomatic Department, The National Hospital (Rikshospitalet), Oslo 1 (Norway) Participant friends of the 12th European Conference for Psychosomatic Research, you by your presence and active participation in all the activities during these days, have justified the convening of this and previous conferences and also future ones.

At the moment we are at the deathbed of this conference and the farewell party is an occasion of regret. When you have worked and leisured with good friends for four days, mourning prevails on the inevitable day of parting.

When I welcomed you on the first day I gave a short historical review of the earliest days of these conferences from which I have gained so much in the area of psychosomatic research and many personal friends.

We of the organizing committee believe we have attained a major part of our objectives - both in the scientific and social programmes. It is up to you to judge whether we have been successful in our strivings.

The difference between the personal experience of grief and our feelings today is - and I will use a slightly adapted version of a popular song - We shall meet again, we know where and we know when.

I want to conclude with a mention of what I experienced in Japan. There they never have farewell parties

only 'see-you-again-parties'

so by carrying over this tradition to BodథS I will end by using the poetic and musical version of this by saying: Sayonara. 